\title{
The impact of homocysteine level on methotrexate induced neurotoxicity in children treated with St. Jude total XV acute lymphoblastic leukemia protocol
}

\author{
Wael Zekri' ${ }^{1}$, Mohamed Sedky Mahmoud Sedky², Mona Khalifa ${ }^{3}$, Sanaa Kenawy ${ }^{4}$ \\ ${ }_{1}^{1}$ Department Pediatrics Oncology, National Cancer Institute, Cairo, Egypt \\ ${ }^{2}$ Department of Pediatrics, National Research Centre, Guiza, Egypt \\ ${ }^{3}$ Department of Pharmacy, National Cancer Institute Cairo University, Cairo, Egypt \\ ${ }^{4}$ Department of Pharmacology and Toxicology, Faculty of Pharmacy, Cairo University, Cairo, Egypt
}

Received October 15, 2015; Revised January 10, 2016; Accepted January 23, 2016; Published Online February 03,2016

\section{Original Article}

\begin{abstract}
Purpose: Methotrexate (MTX) is an antimetabolite that is routinely used in the treatment of hematological malignancies and during its metabolism leads to hyperhomocysteinemia that is associated with neurotoxicity. The purpose of this prospective study is to determine whether the increase in plasma homocysteine (Hcy) concentration is related to MTX-induced neurotoxicity. Methods: We investigated these changes for both newly diagnosed acute lymphoblastic leukemia (ALL) and lymphoblastic lymphoma (LL) pediatric patients treated at the National Cancer Institute, Egypt. They were treated according to St. Jude total XV protocol to receive 2.5 or $5 \mathrm{~g} / \mathrm{m}^{2}$ MTX as a phase of consolidation and were selected between October 2009 and January 2010. Results: Twenty-nine patients were analyzed, M/F: 20/9, the mean age was $8+/-4.4$ years. Hcy level above $15 \mu \mathrm{mol} / \mathrm{L}$ was considered positive. Hcy levels mean at diagnosis, pre $1^{\text {st }}$ HD MTX, post $1^{\text {st }}$ HDMTX, Pre $2^{\text {nd }} H D M T X$, Post $2^{\text {nd }} H D M T X$ were $12.10 \mu \mathrm{mol} / \mathrm{L} \pm 4.17,6.90 \mu \mathrm{mol} / \mathrm{L} \pm 3.02$, $17.59 \mu \mathrm{mol} / \mathrm{L} \pm 6.00,7.21 \mu \mathrm{mol} / \mathrm{L} \pm 2.73$ and $13.74 \mu \mathrm{mol} / \mathrm{L} \pm 4.75$ respectively. Seventeen patients $(58 \%)$ had features suggestive of neurotoxicity. Positive Hcy levels were associated with neurotoxicity $\mathrm{p}=0.05$, higher HDMTX $5 \mathrm{~g} / \mathrm{m}^{2} P=0.023$. A highly significant relation was found between initial Hcy level at diagnosis and final Hcy level $p=0.001$; the same as between Hcy level Post $1^{\text {st }}$ HDMTX and that Post $2^{\text {nd }}$ HDMTX with $p=0.006$. Conclusion: plasma Hcy concentration was significantly elevated after HDMTX administration and this elevation is associated with the observed neurotoxicity. Whether the elevation in Hcy concentration can prove an informative biomarker for neurotoxicity requires additional testing with other MTX regimens.
\end{abstract}

Keywords: Homocysteine; High Dose Methotrexate; Neurotoxicity; Acute Lymphoblastic Leukemia; Lymphoblastic Lymphoma

\section{Introduction}

Methotrexate (MTX) is a folic acid antagonist used since many years in the treatment of hematological malignancies. Its high dose (HD MTX) was prompted for the hematological, central nervous system (CNS) and testicular prophylaxis. ${ }^{1-6}$

MTX is an inhibitor of dihydrofolate reductase (DHFR) resulting in a cellular depletion of tetrahydrofolates
(THF) that are normally essential for the conversion of Homocysteine (Hcy) to methionine. This results into hyperhomocysteinemia ${ }^{7-10}$ that is associated with neurotoxicity ${ }^{11}$ and has been reported for years in the medical literature to present in acute, sub- acute or chronic syndromes ${ }^{12,}{ }^{13}$. It may be transient and reversible but severe neurological disorders leading to coma or even death may occur as well. ${ }^{14-21}$ 
In this study, assessment of the changes in Hcy concentration in plasma was done for newly diagnosed acute lymphoblastic leukemia (ALL) and lymphoblastic lymphoma (LL) pediatric patients treated with HDMTX. The purpose of the study is to determine whether the increase in plasma Hcy concentration is related to MTX-induced neurotoxicity.

\section{Methods and Materials}

Pediatric patients newly diagnosed as ALL or non-Hodgkin's LL, treated at the National Cancer Institute, Cairo University, Egypt were the subject of this prospective study. They were treated according to St. Jude total XV protocol to receive $>1 \mathrm{~g} / \mathrm{m}^{2}$ MTX according to hematological and CNS initial status and disease stratification. ${ }^{22}$ They were selected between $1^{\text {st }}$ of October 2009 and end of January 2010 to assess the correlation between the Hcy level and MTX induced neurotoxicity. The local institute ethical committee approved the study and an informed consent was obtained from the patients guardians prior to their inclusion in the study.

\subsection{Consolidation treatment}

After the patient has achieved remission induction following a 6-week chemotherapeutic treatment including triple intrathecal therapy ${ }^{22}$, consolidation consisted of HDMTX given every 2 weeks. The HD MTX (5 $\mathrm{g} / \mathrm{m}^{2}$ or $2.5 \mathrm{~g} / \mathrm{m}^{2}$ over 24 hours whether standard/high- SR/HR- or low-risk -LR- arms respectively), was given the $1^{\text {st }}$ day in association with the same triple intrathecal therapy including aracytine (Arac), hydrocortisone (HC) and MTX (Table 1). Folinic acid rescue was given intravenously at a dose of 15 $\mathrm{mg} / \mathrm{m}^{2}$ for standard/high-risk patients or $10 \mathrm{mg} / \mathrm{m}^{2}$ for low-risk patient. It started 42 hours later and was given every 6 hours with modifications according to a specific schedule. ${ }^{22}$ Oral 6-mercaptopurine (6MP), $50 \mathrm{mg} / \mathrm{m}^{2} /$ day was associated for 8 weeks to all risk groups.

Table 1: Details of consolidation phase of the protocol.

\begin{tabular}{|c|c|}
\hline Agent, dosage, and routes of administration & Schedule day of consolidation \\
\hline $\begin{array}{l}\text { HDMTX } 5 \mathrm{~g} / \mathrm{m}^{2} \text { for SR or HR patients, } \\
2.5 \mathrm{~g} / \mathrm{m}^{2} \text { for LR patients administered } 24 \text { hours IVI }\end{array}$ & D1,15,29 and 43 \\
\hline 6-Mercapto Purine $50 \mathrm{mg} / \mathrm{m}^{2} /$ day $\mathrm{PO}$ & D1 to 56 \\
\hline $\begin{array}{l}\text { TIT age dependent: MTX } 8,10,12 \mathrm{mg}, \mathrm{HC} 16,20,24 \mathrm{mg} \text {, Arac } \\
24,30,36 \mathrm{mg} \text { for ages } 1 \text { to } 1.99,2 \text { to } 2.99 \text {, and } \geq 3 \text { year old } \\
\text { respectively }\end{array}$ & $\mathrm{D} 1,15,29,43$ \\
\hline
\end{tabular}

Arac: Aracytine; D: Day; HDMTX: High Dose Methotrexate; HR: High risk; HC: Hydrocortisone; IVI: IntraVenous Infusion; LR: Low Risk; MTX: Methotrexate; PO: Per Oral; SR: Standard Risk; TIT: Triple intrathecal.

For HDMTX, one tenth of the total HDMTX loading dose was given over one hour infusion and the remaining nine tenth of the dose were given via continuous infusion over 23 hours. Before HDMTX administration, IV prehydration crystalloid infusion (at $100 \mathrm{ml} / \mathrm{m}^{2} /$ hour for low risk and $125 \mathrm{ml} / \mathrm{m}^{2} /$ hour for standard/high risk) with sodium bicarbonate given over 12 hours. Patients started HD MTX if urine PH was $\geq 6.5 .^{23}$

Folinic acid rescue was given at hour 42 from the start of HDMTX administration. The low dose group received 10 $\mathrm{mg} / \mathrm{m}^{2}$ of leucovorin every 6 hours for 5 doses, while the standard and high risk groups received $15 \mathrm{mg} / \mathrm{m}^{2}$ every 6 hours for 5 doses. The folinic acid dose was adjusted if the methotrexate plasma concentration was $\geq 1 \mu \mathrm{M}$ at hour 42 or $\geq 0.1 \mu \mathrm{M}$ at hour $68 .^{23}$

\subsection{Homocysteine assay}

Hcy measures were timed at diagnosis and relative to the HDMTX treatment (Figure 1). Blood (3 to $4 \mathrm{~mL}$ ) was collected in EDTA tubes at diagnosis, immediately before $1^{\text {st }}$ and $2^{\text {nd }}$ high dose MTX and 42 hours after each of them but before leucovorin treatment. The samples were stored at $-20^{\circ} \mathrm{C}$ till time of analysis. Homocysteine was estimated using the Hcy enzyme immunoassay
(EIA) kit (Axis-shield, UK) according to the method described by Frantzen et al. 1998. ${ }^{24}$

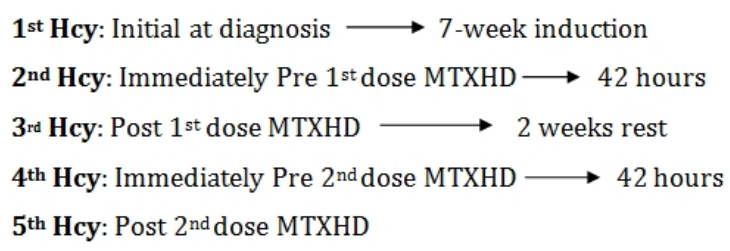

Figure 1: Timing of homocysteine level evaluation.

Any increase in Hcy level above $15 \mu \mathrm{mol} / \mathrm{L}$ following at least one of the two HDMTX, the final Hcy value was considered positive. However, normal levels (5 - 15 $\mu \mathrm{mol} / \mathrm{L}$ ) were considered negative when Hcy level after both $1^{\text {st }}$ and $2^{\text {nd }}$ HDMTX were negative.

\subsection{Clinical neurotoxicity}

Neurotoxicity was evaluated from the results of clinical neurological examination. This was carried out initially at diagnosis and every other week coinciding with HDMTX during the consolidation phase. The target was to elicit any abnormal cognitive, motor or sensory findings. Moreover to detect any increase in intracranial tension in the form of headache, vomiting, blurring of 
vision or signs of meningeal irritation and finally to find out any cranial nerve affection. These were assessed using a form based on common terminology criteria for adverse events version 4.0 CTCAE, national institutes of health, national cancer institute. ${ }^{25}$

Neurotoxicity was evaluated to be positive and given a score I when was present within one day of methotrexate infusion and included one of the following: severe intractable vomiting $>$ thrice not gastro intestinal tract (GIT) induced, headache, low activity, speech impairment, memory impairment, disturbed level of consciousness, convulsions, syncopal attack (not cardiovascular induced) and coma. In its absence the clinical score was zero.

\subsection{Radiological neurotoxicity}

Radiological neurotoxicity was evaluated from the results of brain magnetic resonance imaging (MRI) findings. A base line brain MRI was initially carried out at diagnosis and subsequently at the end of consolidation phase 2 weeks after the last HD MTX and intrathecal therapy. All cases were examined by using 1.5 Tesla superconducting MR imager (magnotom ESPREE 1.5 T, Erlangen, Siemens, Germany).

After intravenous administration of Gadolonium -DTPA $0.3 \mathrm{mg} / \mathrm{kg}$ contrasted enhanced T1W1 in axial, sagittal and coronal places were obtained.

Radiological methotrexate toxicity was to be considered positive and given a score I at the presence of one or more of the following: demyelination, necrotizing lesions, mineralizing microangiopathy, vascular complications, cerebral infarcts, leukencephalopathy, white matter lesions or atrophy. In its absence the score was zero.

If both clinical and radiological examination were of score zero, the MTX neurotoxicity net result was considered negative and given a grade of I. If at least one of both was score I, MTX neurotoxicity net result was considered positive and given a grade of II. If both were of score I, the MTX neurotoxicity net result was considered positive and given a grade of III.

\subsection{Statistical methods}

Data was analyzed using SPSS win statistical package version 20 (SPSS Inc., Chicago, IL). Numerical data were expressed as mean and standard deviation. Comparisons between means where carried out using one-way analysis of variance (ANOVA) test followed by Dunnett test for multiple comparisons.

Qualitative data were expressed as frequency and percentage. Chi-square test (Fisher's exact test) was used to examine the relation between qualitative variables. For quantitative data, comparison between two groups was done using either student t-test or Mann-Whitney test (non-parametric t-test) as appropriate. Values of pre and post assessments were analyzed by paired t-test or wilcoxon signed rank test. $P$-value $\leq 0.05$ was considered significant.

\section{Results}

Out of 40 cases, 29 cases were newly diagnosed ALL or LL. Of them, 20 were males and 9 were females. Their age ranged from 2 to 17 with a mean of $8 \pm 4.4$ years. Eleven patients were excluded from analysis as they did not complete the study. The patient's characteristics are shown in Table 2 and 3.

\subsection{Plasma Hcy concentrations at different check points}

Regarding the final Hcy value, 18 cases (62\%) were with positive (above $15 \mu \mathrm{mol} / \mathrm{L}$ ) values corresponding to increase Hcy levels after at least one of the two HDMTX cycles.

In this study the results of Hcy mean levels at diagnosis, pre first HD MTX, post first HDMTX, Pre second HDMTX, Post second HDMTX were $12.10 \mu \mathrm{mol} / \mathrm{L} \pm 4.17,6.90$ $\mu \mathrm{mol} / \mathrm{L} \pm 3.02,17.59 \mu \mathrm{mol} / \mathrm{L} \pm 6.00,7.21 \mu \mathrm{mol} / \mathrm{L} \pm 2.73$ and $13.74 \mu \mathrm{mol} / \mathrm{L} \pm 4.75$ respectively as shown in (Figure 2).

Table 2: Patients demographic and clinical characteristics.

\begin{tabular}{lll}
\hline \hline Patient characteristics & No. & (\%) \\
\hline $\begin{array}{l}\text { Total number of patients } \\
\text { Gender }\end{array}$ & 29 & 100 \\
Male & 20 & 69 \\
Female & 9 & 31 \\
Age (years) & & \\
$\leq 10$ & 20 & 69 \\
$>10$ & 9 & 31 \\
Diagnosis & & \\
ALL SR & 18 & 62 \\
ALL LR & 9 & 31 \\
NHL & 2 & 7 \\
MTX dose, mg/m ${ }^{2}$ & & \\
2500 & 9 & 31 \\
5000 & 20 & 69 \\
Immunophenotype (Lineage) & & \\
B-cell & 21 & 72.4 \\
T-cell & 8 & 27.6 \\
Risk group (Arm) & & \\
SR (ALL+NHLL) & 20 & 69 \\
LR & 9 & 31 \\
CNS Status & & \\
CNS 1 & 21 & 72.4 \\
CNS 2 & 6.9 \\
CNS 3 & 2 & 20.7 \\
\hline \hline
\end{tabular}


Table 3: Patients with clinical and radiological neurological assessment.

\begin{tabular}{|c|c|c|c|c|c|c|c|c|c|c|c|c|}
\hline \multirow[t]{3}{*}{ UPN } & \multirow[t]{3}{*}{ Diagnosis } & \multirow{3}{*}{$\begin{array}{l}\text { MTX dose } \\
\mathrm{g} / \mathrm{m}^{2}\end{array}$} & \multirow[t]{3}{*}{ Age } & \multirow[t]{3}{*}{ CNS } & \multirow{3}{*}{$\begin{array}{l}\text { C. N. } \\
\text { score }\end{array}$} & \multirow{3}{*}{$\begin{array}{l}\text { R. N. } \\
\text { score }\end{array}$} & \multirow{3}{*}{$\begin{array}{l}\text { NNR } \\
\text { grade }\end{array}$} & \multicolumn{5}{|c|}{ Blood sample Hcy in $\mu \mathrm{mol} / \mathrm{L}$} \\
\hline & & & & & & & & \multirow[t]{2}{*}{ Initial } & \multicolumn{2}{|c|}{$1^{\text {st }}$ MTX HD } & \multicolumn{2}{|c|}{$2^{\text {nd }}$ MTX HD } \\
\hline & & & & & & & & & Pre & Post & Pre & Post \\
\hline 1 & ALL SR & 5 & 10 & I & 1 & 0 & II & 12.5 & 10.5 & 21 & 9.5 & 17 \\
\hline 2 & NHL Tcell & 5 & 15 & I & 1 & 0 & II & 12 & 11 & 22 & 10.5 & 19 \\
\hline 3 & NHL LL B & 5 & 3 & I & 1 & 0 & II & 23,14 & 6 & 19 & 6.5 & 12.5 \\
\hline 4 & ALL LR & 2.5 & 4 & I & 1 & 0 & II & 12.5 & 8 & 21.5 & 9 & 15 \\
\hline 5 & ALL LR & 2.5 & 3 & II & 1 & 0 & II & 7.5 & 5 & 9.5 & 6.5 & 8.5 \\
\hline 6 & ALL SR & 5 & 14 & II & 1 & 0 & II & 8 & 5 & 11 & 4 & 7.5 \\
\hline 7 & ALL LR & 2.5 & 3 & II & 1 & 0 & II & 8.5 & 6 & 16.5 & 7 & 11 \\
\hline 8 & ALL SR & 5 & 5 & I & 1 & 0 & II & 10 & 6 & 14.5 & 8.5 & 13 \\
\hline 9 & ALL Tcell & 5 & 10 & I & 1 & 0 & II & 12.5 & 11 & 24 & 11 & 17 \\
\hline 10 & ALL Tcell & 5 & 13 & I & 1 & 0 & II & 12.5 & 8 & 20 & 8.5 & 16 \\
\hline 11 & ALL SR & 5 & 17 & I & 1 & 0 & II & 14 & 12 & $34.5,36$ & 11 & 22 \\
\hline 12 & ALL LR & 2.5 & 5 & I & 1 & 0 & II & 22,22 & 7 & 14 & 7.5 & 20,25 \\
\hline 13 & ALL SR & 5 & 9 & I & 1 & 1 & III & 14 & 12 & 24 & 12.5 & 18 \\
\hline 14 & ALL SR & 5 & 11 & II & 1 & 1 & III & 12.5 & 5.5 & 14.5 & 6.5 & 15 \\
\hline 15 & ALL SR & 5 & 5 & I & 0 & 1 & II & 11 & 3.5 & 19 & 4 & 10 \\
\hline 16 & ALL Tcell & 5 & 11 & II & 0 & 1 & II & 9 & 4 & 12.5 & 6.5 & 13 \\
\hline 17 & ALL Tcell & 5 & 4 & III & 0 & 1 & II & 12 & 6 & 16 & 7 & 12.5 \\
\hline 18 & ALL Tcell & 5 & 5 & I & 0 & 0 & I & 8 & 3.5 & 12.5 & 6 & 10 \\
\hline 19 & ALL Tcell & 5 & 5 & I & 0 & 0 & I & 9.5 & 4 & 12.5 & 3 & 7 \\
\hline 20 & ALL LR & 2.5 & 9 & I & 0 & 0 & I & $10,9.5$ & $9.5,12$ & $9.5,12$ & 10,8 & $12.5,8.5$ \\
\hline 21 & ALL LR & 2.5 & 7 & I & 0 & 0 & I & 6.5 & 2,5 & 7,8 & 3 & 6 \\
\hline 22 & ALL SR & 5 & 15 & III & 0 & 0 & I & 10.5 & 5.5 & 22 & 5.5 & 12 \\
\hline 23 & ALL SR & 5 & 2 & I & 0 & 0 & I & 14 & 11 & 24 & 11.5 & 19 \\
\hline 24 & ALL Tcell & 5 & 5 & I & 0 & 0 & I & 11 & 3.5 & 12 & 4 & 8 \\
\hline 25 & ALL SR & 5 & 13 & I & 0 & 0 & I & 16 & 11 & 24 & 11 & 18 \\
\hline 26 & ALL LR & 2.5 & 4 & I & 0 & 0 & I & 12 & 4 & 21.5 & 5 & 16 \\
\hline 27 & ALL LR & 2.5 & 5 & I & 0 & 0 & I & $5,21.5$ & 9.5 & 16 & 7.5 & 18 \\
\hline 28 & ALL LR & 2.5 & 9 & I & 0 & 0 & I & 11.5 & 6 & 22.5 & 5 & 13 \\
\hline 29 & All SR & 5 & 13 & II & 0 & 0 & I & 7 & 4 & 9.5 & 3.5 & 7 \\
\hline
\end{tabular}

MTX: Methotrexate; CNS: Central Nervous System; C.N: Clinical Neurotoxicity; R.N: Radiological Neurotoxicity; NNR: Neurotoxicity Net Result

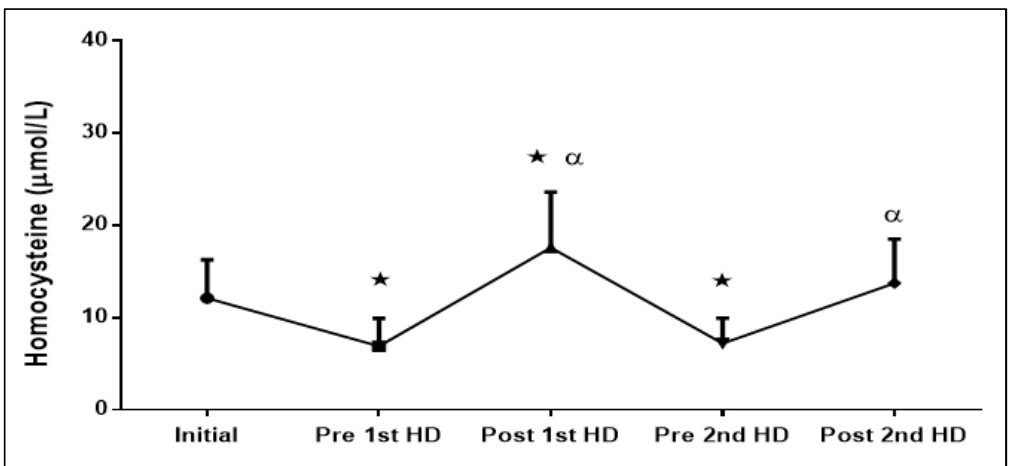

Figure 2: Homocysteine levels at initial (diagnosis) and during the consolidation phase HDMTX.

*Significantly different from diagnosis (initial) value at $P$ $\leq 0.05, \alpha$ significantly different from the corresponding pre administration value at $P \leq 0.05$.

\subsection{Methotrexate-induced neurotoxicity}

Neurotoxicity was assessed qualitatively as the aim was to correlate it with the Hcy level. After HDMTX administration, 17 (58\%) patients had features suggestive of neurotoxicity with newly developed changes in either MRI findings or clinical neurological examination or both of them. Clinical neurological manifestations were shown in 14 patients where it was the solitary finding in 12 patients and associated to MRI changes in the remaining 2 patients. On the other hand
MRI changes were shown in 5 patients where it was associated to clinical neurological findings in 2 patients and as a solitary finding in the remaining 3 patients Table 3.

\subsection{Correlation between Hcy levels and various factors}

A. Final positive Hcy: A highly significant correlation was found between final positive Hcy value $(>15 \mu \mathrm{mol} / \mathrm{L})$ whenever detected at least once in relation to HDMTX and the development of neurotoxicity ( $p=0.05$ ). The same was found between final positive Hcy value and the HD MTX dose whether $5 \mathrm{~g} / \mathrm{m}^{2}$ or $2.5 \mathrm{~g} / \mathrm{m}^{2}(P=$ 
0.023). However, Hcy was positive if age $\leq 10$ years and CNS I or II, but not statistically significant Table 4.

A highly significant relation was found between final Hcy level and initial Hcy level as in 11 patients, the initial Hcy level was $9 \mu \mathrm{mol} / \mathrm{L}+/-1.82$ SD. This corresponded to negative final Hcy level, while in 18 patients; the initial level was $14 \mu \mathrm{mol} / \mathrm{L}+/-4.09$ SD. This corresponded to positive final Hcy level $p=$ 0.001 .

B. Hcy at different checkpoints: A significant relation between Hcy level post $1^{\text {st }}$ HDMTX and Hcy level post $2^{\text {nd }}$ HDMTX as $(p=0.006)$ Table 5.

Table 4: Correlation between the final Hcy level and various prognostic factors.

\begin{tabular}{|c|c|c|}
\hline MTX Neurotoxicity $\quad p=0.05$ & \multicolumn{2}{|c|}{ Final Hcy value } \\
\hline & Negative $(5-15 \mu \mathrm{mol} / \mathrm{L})$ & Positive $>15 \mu \mathrm{mol} / \mathrm{L}$ \\
\hline No neurotoxicity & $9(31 \%)$ & $5(17 \%)$ \\
\hline Presence of neurotoxicity & $2(7 \%)$ & $13(45 \%)$ \\
\hline MTX Dose $\quad p=0.023$ & & \\
\hline $2.5 \mathrm{~g} / \mathrm{m}^{2}$ & $6(21 \%)$ & $3(10 \%)$ \\
\hline $5 \mathrm{~g} / \mathrm{m}^{2}$ & $5(17 \%)$ & $15(52 \%)$ \\
\hline$p=0.41$ & & \\
\hline$\leq 10$ years & $9(31 \%)$ & $11(38 \%)$ \\
\hline$>10$ years & $2(7 \%)$ & $7(24 \%)$ \\
\hline CNS Status & & \\
\hline I & $7(24 \%)$ & $14(48 \%)$ \\
\hline II & $2(7 \%)$ & $4(14 \%)$ \\
\hline III & $2(7 \%)$ & $(0 \%)$ \\
\hline
\end{tabular}

Table 5: Correlation between Hcy levels post $2^{\text {nd }}$ and $1^{\text {st }}$ HDMTX.

\begin{tabular}{clc}
\hline \hline Hcy level post 2 $2^{\text {nd }}$ HDMTX & \multicolumn{2}{c}{ Hcy level post 1st } \\
\cline { 2 - 3 }$P=0.006$ & Negative & Positive \\
Negative & 11 patients $(38 \%)$ & $7(24 \%)$ \\
Positive & $1(3 \%)$ & $10(34 \%)$ \\
\hline \hline
\end{tabular}

\subsection{Correlation between neurotoxicity and various factors}

No significant relation was found between MTX neurotoxicity and various factors including age, MTX dose, patients CNS status and initial Hcy levels. Table 6

Table 6: Correlation between neurotoxicity and various variables.

\begin{tabular}{lll}
\hline \hline & \multicolumn{2}{c}{ MTX neurotoxicity } \\
\cline { 2 - 3 } $\begin{array}{ll}\text { Age }(p=0.427) \\
\text { s 10 years }\end{array}$ & Negative & Positive \\
$>10$ & $11(38 \%)$ & $9(31 \%)$ \\
MTX Dose $(p=0.7)$ & $3(10 \%)$ & $6(21 \%)$ \\
2.5 g & $5(17 \%)$ & $4(14 \%)$ \\
5 g & $9(31 \%)$ & $11(38 \%)$ \\
CNS Status $(p=0.092)$ & & \\
I & $11(38 \%)$ & $10(34 \%)$ \\
II & $1(3 \%)$ & $5(17 \%)$ \\
III & $2(7 \%)$ & $0(0 \%)$ \\
\hline \hline
\end{tabular}

Moreover, there was no correlation between MTX neurotoxicity and initial Hcy levels, as 14 patients showed a mean of $11 \mu \mathrm{mol} / \mathrm{L}+/-3.69$ SD corresponding to negative neurotoxicity oppositely to $13 \mu \mathrm{mol} / \mathrm{L} \mathrm{+/-}$ 4.54 SD corresponding to positive neurotoxicity in 15 patients.

\section{Discussion}

In our study, we found a statistically significant correlation between higher plasma Hcy levels and higher dose of MTX $5 \mathrm{~g}$ versus $2.5 \mathrm{~g}$ and patients with neurotoxicity either clinically or radiologically or both. Kishi et al. 2003, recorded a significant higher plasma Hcy levels among patients with seizures following HD MTX. $^{26}$ The same as for an increased risk for encephalopathy after the administration of HD MTX and coinciding with higher MTX level at hour 42 and a higher Hcy concentration in the 1st HD MTX.27 Hyperhomocysteinemia is classified as mild (15-30 $\mu \mathrm{mol} / \mathrm{L})$, moderate $(31-100 \mu \mathrm{mol} / \mathrm{L})$ or severe $(>100$ $\mu \mathrm{mol} / \mathrm{L})^{28}$ However, the correlation between neurotoxicity and higher level of Hcy was not proved after the administration of MTX 1 or $3 \mathrm{gm} / \mathrm{m}^{2}{ }^{29}$

In the current study, Hcy levels post $1^{\text {st }}$ HDMTX were higher than their levels post $2^{\text {nd }}$ HDMTX and both were higher than their corresponding levels prior to HDMTX. These levels prior to HDMTX were however lesser than those at diagnosis. This goes with the higher baseline Hcy level before therapy among our patients that might have probably reflected their disease burden and occasional folate deficiency. ${ }^{8}$ However, such baseline differences between risk groups were shown by the end of a 6-week remission induction therapy in other 
studies. ${ }^{26}$ In the study of Kubota et al. ${ }^{29}$ a significant rise of the mean Hcy levels at 24 hours was observed as compared to those before HDMTX treatment, then at 48 and 72 hours there were slight decreases in Hcy levels but these values were still significantly higher than the initial levels. ${ }^{29}$

In the current study more than half of the cases developed neurotoxicity attributed to MTX. It included mainly solitary clinical manifestations representing 4 times the solitary radiological manifestations and 6 times combined clinical and radiological ones. These results might be due to over expression of clinical manifestations especially if confounded with GI manifestations of MTX toxicity. In other studies, neurotoxicity was observed after the administration of HDMTX $\left(2 \mathrm{~g} / \mathrm{m}^{2}\right.$ or $\left.5 \mathrm{~g} / \mathrm{m}^{2}\right)$ to children with newly diagnosed ALL. ${ }^{30-31}$ Bhojwani et al. collected data from patients with ALL enrolled onto the total therapy XV study. ${ }^{27}$ They observed that $3.8 \%$ of the patients developed MTX-related subacute neurotoxic events during the consolidation and the continuation phase. Most episodes were brief, but ataxia persisted for 4 weeks. Moreover, Faganel et al. conducted a study on patients diagnosed with ALL and T-cell lymphoma. Neurotoxicity was observed in $23 \%$ of the patients. ${ }^{32}$

\section{Conclusion}

In conclusion, the results of the present study showed that plasma Hcy concentration was significantly elevated after HDMTX administration and this elevation is related to the observed neurotoxicity. Whether the elevation in Hcy concentration can prove an informative biomarker for neurotoxicity requires additional testing with alternative regimens of MTX.

\section{Conflict of interest}

The authors declare that they have no conflicts of interest. The authors alone are responsible for the content and writing of the paper.

\section{Acknowledgement}

The authors acknowledges Prof. Dr. Abdel Rahman Nabawy Zekri, Deaprtment of Tumor Biology NCI, Egypt, for his help and guidance in the analysis of the blood homocysteine level during the preparation of this manuscript.

\section{References}

1. Pui CH, Howard SC. Current management and challenges of malignant disease in the CNS in paediatric leukemia. Lancet Oncol. 2008; 9: 257-68.

2. Graham ML, Shuster JJ, Kamen BA, et al. Changes in red blood cell methotrexate pharmacology and their impact on outcome when cytarabine is infused with methotrexate in the treatment of acute lymphocytic leukemia in children: a pediatric oncology group study. Clin Cancer Res. 1996; 2:331-7.

3. Whitehead VM, Vuchich MJ, Cooley L, et al. Translocations involving chromosome 12p11-13, methotrexate metabolism, and outcome in childhood B-progenitor cell acute lymphoblastic leukemia: a Pediatric Oncology Group study. Clin Cancer Res. 1998; 4:183-8.

4. Plotkin SR, Betensky RA, Hochberg FH, et al. Treatment of relapsed central nervous system lymphoma with high-dose methotrexate. Clin Cancer Res. 2004; 10:5643-6.

5. Rau T, Erney B, Göres R, et al. High-dose methotrexate in pediatric acute lymphoblastic leukemia: impact of ABCC2 polymorphisms on plasma concentrations. Clin Pharmacol Ther. 2006; 80:468-76.

6. Reddick WE, Glass JO, Helton KJ, et al. Prevalence of leukoencephalopathy in children treated for acute lymphoblastic leukemia with high-dose methotrexate. AJNR Am J Neuroradiol. 2005; 26:1263-9.

7. Refsum H, Ueland PM, Kvinnsland S. Acute and long-term effects of high-dose methotrexate treatment on homocysteine in plasma and urine. Cancer Res. 1986; 46:5385-91.

8. Refsum H, Wesenberg F, Ueland PM. Plasma homocysteine in children with acute lymphoblastic leukemia: changes during a chemotherapeutic regimen including methotrexate. Cancer Res. 1991; 51:828-35.

9. Becker A, Vezmar S, Linnebank M, et al. Marked elevation in homocysteine and homocysteine sulfinic acid in the cerebrospinal fluid of lymphoma patients receiving intensive treatment with methotrexate. Int J Clin Pharmacol Ther. 2007;45:504-15.

10. Vezmar S, Schüsseler P, Becker A, et al. Methotrexate-associated alterations of the folate and methyl-transfer pathway in the CSF of ALL patients with and without symptoms of neurotoxicity. Pediatr Blood Cancer. 2009; 52:26-32.

11. Tufekci $\mathrm{O}$, Yilmaz S, Karapinar TH, et al. A rare complication of intrathecal methotrexate in a child with acute lymphoblastic leukemia. Pediatr Hematol Oncol. 2011;28:517-22.

12. Rollins N, Winick N, Bash R, Booth T. Acute methotrexate neurotoxicity: findings on diffusion-weighted imaging and correlation with clinical outcome. AJNR Am J Neuroradiol. 2004; 25:1688-95.

13. Haykin ME, Gorman M, van Hoff J. Diffusion-weighted MRI correlates of subacute methotrexate-related neurotoxicity. J Neurooncol. 2006;76:153-7. 
14. Bleyer WA. Neurologic sequelae of methotrexate and ionizing radiation: a new classification. Cancer Treat Rep. 1981; 65 Suppl 1:89-98.

15. Mahoney DH Jr, Shuster JJ, Nitschke R, et al. Acute neurotoxicity in children with B-precursor acute lymphoid leukemia: an association with intermediate-dose intravenous methotrexate and intrathecal triple therapy--a Pediatric Oncology Group study. J Clin Oncol. 1998;16:1712-22.

16. Vezmar S, Becker A, Bode U, Jaehde U. Biochemical and clinical aspects of methotrexate neurotoxicity. Chemotherapy. 2003;49:92-104.

17. Mattson MP, Shea TB. Folate and homocysteine metabolism in neural plasticity and neurodegenerative disorders. Trends Neurosci. 2003; 26:137-46.

18. D'Anci KE, Rosenberg IH. Folate and brain function in the elderly. Curr Opin Clin Nutr Metab Care. 2004; 7:659-64.

19. Reddick WE, Laningham FH, Glass JO, Pui CH. Quantitative morphologic evaluation of magnetic resonance imaging during and after treatment of childhood leukemia. Neuroradiology. 2007; 49:889-904.

20. Hill DE, Ciesielski KT, Sethre-Hofstad L, et al. Visual and verbal short-term memory deficits in childhood leukemia survivors after intrathecal chemotherapy. J Pediatr Psychol. 1997; 22:861-70.

21. Montour-Proulx I, Kuehn SM, Keene DL, et al. Cognitive changes in children treated for acute lymphoblastic leukemia with chemotherapy only according to the Pediatric Oncology Group 9605 protocol. J Child Neurol. 2005, 20:129-33.

22. Pui CH, Campana D, Pei D, et al. Treating childhood acute lymphoblastic leukemia without cranial irradiation. N Engl J Med. 2009; 360:2730-41.

23. Pauley JL, Panetta JC, Crewa KR, et al. Between course targeting of methotrexate exposure using pharmakokinetically guided dosage adjustments. Cancer Chemother. Pharmacol. 2013; 72:369-78.

24. Frantzen f, Faaren AL, Alfheim I, Nordhei AK. Enzyme conversion immunoassay for determining total homocysteine in plasma or serum. Clin Chem. 1998; 44:311-6.

25. Basch E, Reeve BB, Mitchell SA, et al. Development of the National Cancer Institute's patient-reported outcomes version of the common terminology criteria for adverse events (PRO-CTCAE). J Natl Cancer Inst. 2014;106.

26. Kishi S, Griener J, Cheng C, et al. Homocysteine, pharmacogenetics, and neurotoxicity in children with leukemia. J Clin Oncol. 2003; 21:3084-91.

27. Bhojwani D, Sabin ND, Pei D, et al. Methotrexate-induced neurotoxicity and leukoencephalopathy in childhood acute lymphoblastic leukemia. J Clin Oncol. 2014; 32:949-59.

28. Weiss N, Keller C, Hoffmann U, Loscalzo J. Endothelial dysfunction and atherothrombosis in mild hyperhomocysteinemia. Vasc Med. 2002;7:227-39.

29. Kubota M, Nakata R, Adachi S, et al. Plasma homocysteine, methionine and S-adenosylhomocysteine levels following high-dose methotrexate treatment in pediatric patients with acute lymphoblastic leukemia or Burkitt lymphoma: association with hepatotoxicity. Leuk Lymphoma. 2014; 55:1591-5.

30. Erčulj N, Kotnik BF, Debeljak M. Influence of folate pathway polymorphisms on high-dose methotrexate-related toxicity and survival in childhood acute lymphoblastic leukemia. Leuk Lymphoma. 2012; 53:1096-104.

31. Liu SG, Li ZG, Cui L, Gao C, et al. Effects of methylenetetrahydrofolate reductase gene polymorphisms on toxicities during consolidation therapy in pediatric acute lymphoblastic leukemia in a Chinese population. Leuk Lymphoma. 2011;52:1030-40.

32. Faganel Kotnik B, Grabnar I, Bohanec Grabar P, et al. Association of genetic polymorphism in the folate metabolic pathway with methotrexate pharmacokinetics and toxicity in childhood acute lymphoblastic leukaemia and malignant lymphoma. Eur J Clin Pharmacol. 2011;67:993-1006. 